\title{
CAMP attenuates angiotensin-II-induced Egr-1 expression via PKA-dependent signaling pathway in vascular smooth muscle cells
}

\begin{tabular}{|r|l|}
\hline Journal: & Canadian Journal of Physiology and Pharmacology \\
\hline Manuscript ID & cjpp-2017-0035.R1 \\
\hline Manuscript Type: & Article \\
\hline Date Submitted by the Author: & 22-Feb-2017 \\
\hline Complete List of Authors: & $\begin{array}{l}\text { Simo-Cheyou, Estelle; Centre de recherche du CHUM } \\
\text { Youreva, Viktoria; Laboratory of Cell Signaling, Montreal Diabetes Research } \\
\text { Center, ; Research Center of Centre hospitalier de I'Université de Montréal } \\
\text { (CRCHUM), } \\
\text { Srivastava, Ashok; Professor of Medicine and Head, }\end{array}$ \\
\hline Keyword: & Angiotensin-II, Egr-1, cAMP, VSMC, PKA \\
\hline \multicolumn{2}{|c}{} \\
\hline
\end{tabular}




\section{cAMP attenuates angiotensin-II-induced Egr-1 expression via PKA-dependent signaling pathway in vascular smooth muscle cells}

Estelle R. Simo-Cheyou ${ }^{1,2,3}$, Viktoria Youreva ${ }^{1,2}$, Ashok K. Srivastava ${ }^{1,2,3,4}$

${ }^{1}$ Laboratory of cellular signaling, ${ }^{2}$ Research Center-University of Montreal Hospital Center (CRCHUM).

Departments of ${ }^{3}$ Nutrition, and ${ }^{4}$ Medicine, Faculty of Medicine, University of Montreal, Quebec, CANADA.

\section{Address of correspondence:}

Ashok K. Srivastava, Ph.D.

CRCHUM, Tour Viger

900, rue St-Denis

Montréal, (Québec)

H2X 0A9

CANADA

Tel: 514-890-8000 ext. 23604

Fax : 514-412-7648

E-mail:ashok.srivastava@umontreal.ca 


\begin{abstract}
cAMP has been shown to inhibit vascular smooth muscle cell proliferation and exerts a vasculoprotective effect. An upregulation of the early growth response protein-1 (Egr-1) expression has been linked with the development of atherosclerosis and intimal hyperplasia. We have recently demonstrated that angiotensin-II (Ang-II) stimulates Egr-1 expression via $\mathrm{Ca}^{2+/}$ ERK-mediated cAMP-response element binding protein (CREB) activation. However, whether Ang-II-induced signaling leading to Egr-1 expression is modulated by cAMP remains unexplored. Therefore, in the present studies, we have examined the effect of cAMP on Ang-II-induced expression of Egr-1 and associated signaling pathways. Isoproterenol (ISO) and forskolin (FSK) attenuated Ang-II-induced Egr-1 expression in a dose-dependent fashion. In addition, dibutyryl-cAMP and benzoylcAMP, as well as isobutylmethylxanthine, attenuated Ang-II-induced Egr-1 expression. Moreover, inhibition of Ang-II-induced Egr-1 expression was accompanied by an increase in the phosphorylation of the vasodilator-activated phosphoprotein (VASP), and this was associated with a concomitant decrease in ERK phosphorylation. Blockade of PKA using H89 decreased VASP phosphorylation, restored Ang-II-induced ERK phosphorylation, and abolished ISO- and FSK-mediated inhibition of Ang-II-induced Egr-1 expression. In summary, these results suggest that PKA-mediated suppression of Ang-II-induced Egr-1 expression and phosphorylation of ERK may be among the mechanisms by which cAMP exerts its vasculoprotective effects.
\end{abstract}

Keywords: Angiotensin-II, Egr-1, cAMP, VSMC, PKA, ERK, VASP. 


\section{Introduction}

Aberrant proliferation and migration of vascular smooth muscle cells (VSMC) are believed to contribute to abnormal vascular function leading to the pathogenesis of vascular diseases (Rivard and Andres 2000). These events are promoted by elevated concentrations of vasoactive peptides such as angiotensin-II (Ang-II) which plays an important role in vascular function (Montezano et al. 2014; Nakashima et al. 2006). At the cellular level, exaggerated stimulation by Ang-II results in a phenotypic switch of VSMC that progressively differentiate from a contractile state to a synthetic state (Campbell and Campbell 1985). Synthetic VSMC are characterized by hyperproliferative properties and enhanced migratory capacities (Potier et al. 2009). These features induce pathological neointima formation and subsequent vessel narrowing. At the signaling level, elevated levels of Ang-II mediate the hyperactivation of growth promoting signaling pathways involving the mitogen-activated protein kinase (MAPK)-mediated cascade and related transcriptional events (Touyz and Berry 2002) that contribute to the regulation of genes implicated in vascular remodeling (Cipolletta et al. 2010; Duff et al. 1995; Hartney et al. 2011).

Enhanced levels of 3'-5'-cyclic adenosine monophosphate (cAMP) produced via adenylate cyclase (AC) activity have been reported to antagonize vasoactive peptide- and mitogen-induced proliferative responses in VSMC (Begum et al. 2011; Graves et al. 1993; Hewer et al. 2011). One of the major effector involved in transducing cAMPinduced events is protein kinase A (PKA). The $\beta$-agonist isoproterenol (ISO), known to increase cAMP via G-protein-coupled receptor (GPCR)-mediated AC activation, has been demonstrated to inhibit Ang-II-induced VSMC proliferation (Kim et al. 2009). In 
accordance with this, functional abnormalities in the coupling of $\beta$-adrenergic receptor agonism are associated with alterations in the signaling events regulating VSMC proliferation (Gros et al. 2006). Impairments in cAMP-induced signaling have also been correlated with a rise in blood pressure and related dysfunctional features in VSMC (Shahid et al. 2010).

An involvement of the early growth response protein-1 (Egr-1), a zinc finger containing transcription factor, in the pathogenesis of vascular diseases has recently been demonstrated in experimental models of atherosclerosis and vascular injury (Khachigian 2006; Ohtani et al. 2004; Santiago et al. 1999; Vazquez-Padron et al. 2010). The presence of Egr-1 binding motifs within the structure of several pro-atherogenic genes has suggested that Egr-1 modulates vascular physiology in response to several stimuli (McCaffrey et al. 2000). Growth-promoting stimuli and several vasoactive peptides have been demonstrated to enhance Egr-1 expression and activity in VSMC and other vascular cells (Bouallegue et al. 2013; Iyoda et al. 2012; Liu et al. 2013; Youreva et al. 2013; Youreva and Srivastava 2016). With regard to the molecular mechanisms underlying Egr1 expression, we recently demonstrated that Ang-II upregulates Egr-1 levels in VSMC via a pathway that involves calcium signaling components upstream of $\mathrm{ERK}_{1 / 2}$-mediated molecular events (Simo-Cheyou et al. 2017) .

Previous studies showing that deletion of Egr-1 suppresses the vasculoprotective effects of cAMP elevating agents in VSMC have suggested a link between cAMPdependent signaling and Egr-1 expression and activity (Kimura et al. 2014). However, the molecular mechanism by which cAMP-mediated pathway can modulate Ang-IIinduced signaling cascade leading to Egr-1 expression in VSMC remains unexplored. 
Therefore, in the present studies, we have examined the effects of an elevation in the intracellular levels of cAMP on Ang-II-induced signaling upstream of Egr-1 expression in VSMC. 


\section{Materials and methods}

\section{Antibodies and reagents}

Ang-II (\#A9525), forskolin (\#F6886), dibutyryl-cAMP (\#D0260), were purchased from Sigma-Aldrich (St. Louis, MO, USA). N6-Benzoyl-adenosine 3', 5'-cyclic monophosphate sodium salt (BNZ) (\#116802) was purchased from EMD Millipore (Etobicoke, ON, Canada). Phosphorylated $\mathrm{ERK}_{1 / 2}(\# \mathrm{SC} 16982-\mathrm{R})$ antibody was purchased from Santa Cruz Biotechnology (Dallas, TX, USA). Egr-1 (\#4153S), total (\#3112S) and Ser157 phosphorylated VASP (\#3111S), $\beta$-tubulin (\#2146S), and anti-rabbit (\#7074S) antibodies were purchased from Cell Signaling Technology (Beverly, Massachusetts, USA). The enhanced chemiluminescence (ECL) detection system kit was purchased from Perkin Elmer (Montreal, QC, Canada).

\section{Cell culture}

VSMC derived from the medial layer of rat thoracic aortae (A-10 cell line (CRL1476) from ATCC, Manassas, USA) were maintained in culture with Dulbecco's modified eagle medium (DMEM) containing 10\% fetal bovine serum (FBS) and 1\% penicillin/streptomycin at $37^{\circ} \mathrm{C}$ in a humidified atmosphere of $5 \% \mathrm{CO}_{2}$, as described earlier (Bouallegue et al. 2007). Cells between passages 4 and 8 were grown to $80-90 \%$ confluence in 60-mm dishes and incubated in serum and antibiotic-free DMEM 5 hours prior to treatments.

\section{Cell lysis and immunoblotting}

Quiescent A-10 VSMC were incubated in the absence or presence of various reagents for 30 minutes followed by stimulation with $100 \mathrm{nM}$ Ang-II for indicated time periods. The cells were washed three times with ice-cold PBS and lysed in $100 \mu \mathrm{L}$ radio- 
immunoprecipitation (RIPA) buffer. Protein concentration was determined by Bradford assay and $35-45 \mu \mathrm{g}$ of proteins were subjected to $10 \%$ SDS-polyacrylamide gel electrophoresis, transferred to Immobilion-P polyvinylidinedifluoride membranes (Millipore, USA) and incubated with respective primary antibodies as described previously (Youreva and Srivastava 2016). The antigen-antibody complex was detected by horseradish peroxidase-conjugated secondary anti-rabbit antibodies and protein bands were visualized with ECL kit. Equal loading of protein was confirmed by measuring protein levels of $\beta$-tubulin or total proteins. The intensity of the bands was quantified by densitometric analysis using Quantity One Bio-Rad Corp. imaging and Graphpad Prism 5 (San Diego, CA, USA) software programs.

\section{Preparation of cDNA}

Following incubations, total RNA was isolated with Trizol Reagent (Life Technologies, Burlington, ON). RNA concentration was quantified with the Biophotometer (Eppendorf, Mississauga, ON). Absorbances were measured at wavelengths of $260 \mathrm{~nm}$ and $280 \mathrm{~nm}$. The purity of RNA preparation was confirmed when the ratio A260/A280 was comprised in the range 1.8-2.0. cDNA was synthesized from 1 $\mu \mathrm{g}$ of total pure RNA using High Capacity RNA-to-cDNA Kit (Applied Biosystems, Grand Island, NY) as per manufacturer's instructions.

\section{Real-time quantitative polymerase chain reaction (qRT-PCR)}

qRT-PCR was performed with SYBG (Life Technologies, Grand Island, NY, USA) using $1 \mu \mathrm{L}$ of cDNA in a $20 \mu \mathrm{L}$ reaction. Amplification was performed using 7500 fast RT-PCR system (Applied Biosystems, Grand Island, NY). Sequences used to design Egr-1 primers were as follows: forward 5'-CTGCTTCATCGTCTTCCTCTG-3' and 
reverse 5'-GTCAGTGTTGGGAGTAGGAAAG-3'. Egr-1 mRNA expression was measured and normalized with $\beta$-actin mRNA levels using primers: forward 5'TCTTCCAGCCTTCCTTCCT-3' and reverse 5'-CAGCACTGTGTTGGCATAGA-3'.

\section{Statistics}

Statistical analysis was performed by one-way, standard analysis of variance (ANOVA) in conjunction with a Tukey post hoc test. All data are expressed as mean \pm SEM of 3 to 5 independent experiments. The differences between means were considered statistically significant at $p<0.05$. 


\section{Results}

\section{Isoproterenol attenuates Ang-II-induced expression of Egr-1 in A-10 VSMC}

ISO inhibits Ang-II-induced VSMC proliferation and mitogenic signaling in a heme oxygenase-dependent pathway via $\beta 2$ adrenoreceptor-mediated PKA activity (Kim et al. 2009). We have shown earlier that Ang-II is a potent inducer of Egr-1 expression in VSMC (Simo-Cheyou et al. 2017) and, since serum-induced expression of Egr-1 was reported to be downregulated by cAMP-induced signaling in VSMC (Kimura et al. 2014), we examined the effect of ISO on Ang-II-induced Egr-1 expression. As shown in Figure 1, treatment of VSMC with different concentrations of ISO attenuated Ang-IIinduced expression of Egr-1 in a dose-dependent fashion with the maximal inhibitory effect observed at $10 \mu \mathrm{M}$ (Fig.1A). Similar to Egr-1 protein levels, treatment of VSMC with ISO reduced Ang-II-induced increase in Egr-1 mRNA levels in VSMC (Fig.1B).

\section{AC activation by forskolin mimics the effect of isoproterenol on Ang-II-induced upregulation of Egr-1}

Gas-coupled receptor ligands activate AC and thereby elevate the intracellular levels of cAMP. A rise in intracellular cAMP has been reported following treatment of VSMC with ISO (Zhang et al. 1997) and anti-mitogenic properties are attributed to cAMP in VSMC (Kimura et al. 2014). Thus, to confirm the involvement of cAMP in ISO-mediated response, it was of interest to test whether a non-receptor-mediated activation of $\mathrm{AC}$ would exhibit a similar response on the regulation of Ang-II-induced Egr-1 expression. Therefore, we used the AC activator forskolin (FSK), and, as shown in Figure 2A, pre-treatment of VSMC with increasing concentrations of FSK resulted in a 
significant attenuation of Ang-II-induced upregulation of Egr-1 in a dose-dependent fashion. Treatment with FSK alone did not exert any significant effect as compared to untreated cells where Egr-1 protein was barely detectable (Fig.2A). Total $\beta$-tubulin protein levels were not affected by FSK treatment. Similar to isoproterenol, FSK induced an attenuation of Ang-II-induced upregulation of Egr-1 mRNA (Fig.2B). These data suggest the involvement of cAMP in ISO-induced downregulation of Ang-II-induced Egr-1 expression.

\section{Isoproterenol-mediated decrease in Ang-II-induced Egr-1 expression is potentiated by phosphodiesterase inhibition and inversely correlates with VASP phosphorylation}

By catalyzing the transformation of cAMP into AMP, phosphodiesterase (PDE) activity reduces the level of intracellular cAMP. PDE inhibitors delay this degradation and thus prolong the presence of cAMP at elevated concentrations in cells treated with cAMP elevating agents. Therefore, to further define the role of cAMP in ISO-mediated response, it was of interest to test the effect of PDE inhibition on Ang-II-induced Egr-1 expression in the presence or absence of ISO. Cells were pre-treated with $10 \mu \mathrm{M}$ of isobutylmethylxanthine (IBMX), a broad spectrum PDE inhibitor, prior to stimulation with Ang-II. As shown in Figure 3A, heightened levels of Egr-1 observed in response to Ang-II were attenuated by pre-treatment with IBMX suggesting that increase in cAMP levels by PDE inhibition can also attenuate Ang-II-induced signaling leading to Egr-1 expression (Fig.3A). Moreover, simultaneous addition of IBMX along with ISO resulted in a further decrease in Ang-II-induced Egr-1 expression (Fig.3B). Together, these data demonstrated that cAMP plays a key role in ISO-mediated inhibition of Ang-II-induced 
Egr-1 expression. In addition, since the phosphorylation of the vasodilator-stimulated phosphoprotein (VASP) has been used as a marker of cAMP signaling and protein kinase A activation (Butt et al. 1994; Eckert and Jones 2007; Harbeck et al. 2000; Joshi et al. 2011), it was of interest to examine the patterns of VASP phosphorylation associated with reduced Egr-1 levels. We therefore used an antibody able to detect both the $46 \mathrm{kDa}$ total VASP protein and VASP phosphorylated at serine 157 exhibiting a shift at 50kDa due to phosphorylation-induced altered electrophoretic mobility (Butt et al. 1994; Harbeck et al. 2000). Figure 4A and B show that IBMX does not trigger a detectable increase in phosphorylation of VASP as compared to the unstimulated cells (Fig.4A and 4B). However, IBMX-mediated attenuation of Ang-II-induced Egr-1 expression is accompanied with an induction of VASP phosphorylation as measured by the ratio of serine 157 phosphorylated VASP over the total protein (Fig.4A). Furthermore, similar to the additive effect produced towards Egr-1 downregulation, simultaneous treatment with ISO and IBMX resulted in a more robust increase in Ser157 phosphorylation of VASP as compared with individual treatment with either ISO or IBMX (Fig.4B). Taken together, these data demonstrate that sustained elevation of cAMP results in a more potent VASP phosphorylation that correlates with a potentiation of isoproterenol-mediated inhibitory effect on Ang-II-induced Egr-1 expression.

\section{PKA signaling exerts an inhibitory effect on Ang-II-induced Egr-1 expression}

Because increased VASP phosphorylation on serine 157 corresponds to an enhanced PKA activity in several types of cells and since PKA activity interferes with proliferative responses in VSMC (Hewer et al. 2011), we next sought to assess the role of PKA in the attenuation of Ang-II-induced Egr-1 expression. For this purpose, we 
examined the effects of the cell permeable analog of cAMP, dibutyryl cAMP (Db-cAMP) and a cAMP analog that specifically activates PKA in the cells, benzoyl-cAMP (BNZcAMP). As depicted in Figure 5, similar to ISO and FSK, both Db-cAMP and BNZcAMP attenuated Ang-II-induced Egr-1 expression in a dose-dependent fashion (Fig.5A) suggesting the contribution of PKA in downregulating Ang-II-induced Egr-1 expression (Fig.5B).

\section{Blockade of PKA restores Ang-II-induced Egr-1 upregulation in the presence of ISO or FSK}

Next, to further confirm the involvement of PKA in cAMP-induced suppression of Ang-II-induced Egr-1 expression, we investigated the consequence of pharmacological blockade of PKA on ISO- and FSK-mediated inhibitory responses. Cells were treated with $10 \mu \mathrm{M}$ of the PKA inhibitor H89, prior to ISO or FSK pre-treatments followed by Ang-II stimulation for one hour. As depicted in Figure 6 and Figure 7, whereas the increase in Egr-1 observed in the presence of Ang-II is totally blunted by ISO (Fig.6A) and FSK (Fig.7A), blockade of PKA with H89 restored it to an even higher level than that observed with Ang-II alone (Figs.6A and 7A). Interestingly, in the absence of ISO, PKA blockade also resulted in a potentiation of Egr-1 induction suggesting a high basal activity of PKA in A-10 VSMC. A similar effect of H89 treatment on the reversal of Egr1 mRNA expression in the presence of ISO and FSK was also observed (Figs. 6B and 7B). These data indicated that PKA plays a critical role in transducing GPCR-activated or non-receptor-mediated increase in cAMP leading to the suppression of Egr-1 expression in response to Ang-II in VSMC. 


\section{ISO or FSK-mediated phosphorylation of VASP is associated with suppression of Ang-II-induced ERK1/2 phosphorylation}

Since our data demonstrated the participation of PKA in ISO- and FSK-mediated attenuation of Ang-II-induced Egr-1 expression, we sought to determine the signaling changes accompanying this response. ERK-mediated signaling pathways play a key role in mediating the migratory and proliferative responses in VSMC (Xi et al. 1999) and, has been implicated in Egr-1 induction in response to Ang-II as well as several growthpromoting stimuli in VSMC (Cui et al. 2006; Liu et al. 2013; Simo-Cheyou et al. 2017; Youreva and Srivastava 2016). Therefore, based on our results showing that FSK and ISO- mediated suppression of Ang-II-induced Egr-1 expression was associated with an increase in the serine 157 phosphorylation of VASP (Fig.3), it was of interest to examine the effect of H89-mediated blockade of PKA on the degree of phosphorylation of VASP and ERK1/2 in response to the combination of Ang-II and ISO or FSK stimulation. Pretreatments were made prior to Ang-II stimulation for 5 minutes. Results show that addition of ISO (Top panel Fig.8A) or FSK (Top panel Fig.9A) alters the mobility of total VASP (46 kDa to $50 \mathrm{kDa}$ ) depicting an increase in ser 157 phosphorylation, and this increase was accompanied by a reduction in Ang-II-induced ERK1/2 phosphorylation (Middle panels Fig.8A and 9A). H89 treatment decreased VASP phosphorylation with a concomitant restoration of Ang-II-induced ERK1/2 phosphorylation (Fig.8A,C and 9A,C) suggesting that PKA-mediated downregulation of Egr-1 is preceded by a decrease in Ang-II-induced ERK1/2 phosphorylation. Interestingly, similar to Egr-1 expression, Ang-II-induced ERK1/2 phosphorylation was potentiated by blockade of PKA and this correlated with lower levels of serine 157 phosphorylation VASP (Figs.8B and 9B). 
These data suggest that PKA mediates the effects of ISO and FSK on Ang-II-induced Egr-1 expression by attenuating Ang-II-induced ERK1/2 phosphorylation in A-10 VSMC.

\section{Discussion}

In this study, we have demonstrated that $\beta$-adrenergic receptor activation of VSMC by ISO suppressed both protein and mRNA expression of Egr-1 induced by AngII. We also show that FSK, that directly activates AC activity and increases cAMP levels in the cells, as well as Db-cAMP, a cell permeable analogue of cAMP, mimicked ISO in suppressing Ang-II-induced Egr-1 expression. Additionnally, we have demonstrated that increasing cAMP by inhibiting PDE activity in VSMC exerts a similar effect. A large body of evidence has indicated that cAMP exerts a growth inhibitory effect in VSMC and reduces neointima formation in vascular injury (Gusan and Anand-Srivastava 2013; Indolfi et al. 1997; Kim et al. 2009; Lehrke et al. 2015; Palmer et al. 1998; Takahashi et al. 1996). In view of the reported involvement of Egr-1 in neointima formation in vesselinjured models (Lowe et al. 2001; Wang et al. 2013), our studies showing that $\beta$ adrenergic stimulation or cAMP elevating agents potently suppressed Ang-II-induced Egr-1 expression in VSMC support the concept that reduction in the levels of transcription factors such as Egr-1 may be among the molecular mechanisms responsible for vasoprotective effects of cAMP (Dubey et al. 2015; Gusan and Anand-Srivastava 2013; Kimura et al. 2014). Our results have also demonstrated that ISO or IBMX-induced reduction of Egr-1 expression was associated with an increase in serine 157 phosphorylation of VASP, which is a marker of PKA activity (Butt et al. 1994; Eckert and Jones 2007; Harbeck et al. 2000; Joshi et al. 2011), suggesting the involvement of 
PKA activation in this process. The findings that H89, a pharmacological inhibitor of PKA, restored the suppressive effect of ISO and FSK on Ang-II-induced Egr-1 expression have provided additional evidence for a role of PKA in transducing the downstream effects of cAMP in inhibiting Ang-II-stimulated expression of Egr-1. Although an attenuating effect of cAMP in serum-induced Egr-1 expression in VSMC has been reported earlier (Hewer et al. 2011), the present studies have demonstrated for the first time that cAMP signaling via PKA is able to block Ang- II- induced Egr-1 expression in VSMC.

We have shown earlier that ERK1/2 activation is critical to induce protein and mRNA expression of Egr-1 in response to endothelin-1 (ET-1), insulin-like growth factor-1 and Ang-II (Simo-Cheyou et al. 2016; Simo-Cheyou et al. 2017; Youreva and Srivastava 2016). Our data presented here suggest that cAMP/PKA-induced reduction in ERK1/2 activity may contribute to the suppressive effect of cAMP elevating agents on Egr-1 expression because ISO- or FSK-induced suppression of Egr-1 expression caused a concomitant reduction in the level of the phosphorylation of ERK1/2. A similar reduction in ERK1/2 phosphorylation by Db-cAMP in VSMC from SHR aorta has also been reported (Gusan and Anand-Srivastava 2013) and PDE-3A inhibition-induced increase in cAMP has been shown to attenuate ERK1/2 phosphorylation in VSMC (Begum et al. 2011). These authors also reported that PDE-3A-induced reduction in ERK1/2 phosphorylation was associated with an inhibition in the activity of Raf-1 and an increased activity of MAPK phosphatase-1 (MKP-1) (Begum et al. 2011). Raf-1 is an upstream kinase in the $\mathrm{MEK} / \mathrm{ERK} 1 / 2$ signaling cascade and its inhibition results in impaired phosphorylation of ERK1/2. MKP-1, on the other hand, is an ERK1/2-specific- 
protein phosphatase that catalyzes the dephosphorylation and thereby inactivation of ERK1/2. Thus, it may be suggested that ISO- and FSK-induced reduction in ERK1/2 phosphorylation observed in our studies may be mediated through a similar mechanism. Furthermore, our results showing that H89 restored not only attenuated Egr-1 expression but also ERK1/2 phosphorylation indicated that PKA via ERK1/2 signaling pathway contributes to the suppressive effects of ISO and FSK. A similar role of ERK1/2 in adenosine-mediated suppression of VSMC proliferation and expression of cell cycle regulatory proteins in human coronary smooth muscle cells has been suggested (Dubey et al. 2015).

Ang-II signals its downstream responses through the generation of reactive oxygen species (ROS) by activating $\mathrm{NAD}(\mathrm{P}) \mathrm{H}$ oxidases (NOXes) (Nguyen Dinh Cat et al. 2013; Seshiah et al. 2002). Recent reports have shown that Ang-II-induced $\mathrm{H}_{2} \mathrm{O}_{2}$ production was attenuated by FSK or Db-cAMP in PKA-dependent fashion (Zhao et al. 2014). In addition, cAMP elevation by Db-cAMP has also been shown to suppress superoxide generation as well as NOX activity in VSMC isolated from SHR aorta (Gusan and Anand-Srivastava 2013). These authors also noted that Db-cAMP treatment of VSMC resulted in an attenuated tyrosine phosphorylation of the epidermal growth factor receptor (EGF-R) as well as c-Src. We have shown earlier that Ang-II signals protein and DNA synthesis, key markers of hypertrophic and proliferative responses in VSMC and have recently reported that c-Src is essential to trigger ET-1 induced Egr-1 expression (Bouallegue et al. 2009; Simo-Cheyou et al. 2016), thus in view of the key role that ROS generation and tyrosine phosphorylation of EGF-R and c-Src plays in triggering Ang-II 
signaling pathways, it is possible that ability of cAMP-PKA to inhibit these events may be responsible to inhibit ERK 1/2 phosphorylation observed in our studies.

In summary, we have demonstrated that elevating cellular cAMP levels either by GPCR-mediated activation or by other agents attenuated Ang-II-induced Egr-1 expression via a PKA-mediated inhibition of Ang-II-induced ERK1/2 phosphorylation in VSMC. Our findings have revealed a previously unidentified role of PKA system in regulating Ang-II-induced Egr-1 expression and suggest that suppression of Egr-1 expression may be one of the mechanisms by which cAMP exerts its vasculoprotective effects.

\section{GRANTS}

This work was supported by funding from the Canadian Institutes of Health Research (CIHR) operating grant number 67037 to AKS. ERSC was a recipient of a doctoral fellowship from the faculty of graduate and postdoctoral studies of the University of Montreal.

\section{DISCLOSURES}

The authors of this manuscript do not have any conflict of interest to disclose. 
Reference List

Begum, N., Hockman, S., and Manganiello, V. C. 2011. Phosphodiesterase 3A (PDE3A) deletion suppresses proliferation of cultured murine vascular smooth muscle cells (VSMCs) via inhibition of mitogen-activated protein kinase (MAPK) signaling and alterations in critical cell cycle regulatory proteins. J. Biol. Chem. 286 (29): 26238-26249.

Bouallegue, A., Daou, G. B., and Srivastava, A. K. 2007. Nitric oxide attenuates endothelin-1induced activation of ERK1/2, PKB, and Pyk2 in vascular smooth muscle cells by a cGMPdependent pathway. Am.J.Physiol Heart Circ.Physiol. 293 (4): H2072-H2079.

Bouallegue, A., Simo Cheyou, E. R., Anand-Srivastava, M. B., and Srivastava, A. K. 2013. ET-1induced growth promoting responses involving ERK1/2 and PKB signaling and Egr-1 expression are mediated by $\mathrm{Ca} 2+/ \mathrm{CaM}-$ dependent protein kinase-II in vascular smooth muscle cells. Cell Calcium, 54 (6): 428-435.

Bouallegue, A., Vardatsikos, G., and Srivastava, A. K. 2009. Role of insulin-like growth factor 1 receptor and c-Src in endothelin-1- and angiotensin II-induced PKB phosphorylation, and hypertrophic and proliferative responses in vascular smooth muscle cells. Can.J.Physiol. Pharmacol. 87 (12): 1009-1018.

Butt, E., Abel, K., Krieger, M., Palm, D., Hoppe, V., Hoppe, J., et al. 1994. cAMP- and cGMPdependent protein kinase phosphorylation sites of the focal adhesion vasodilator-stimulated phosphoprotein (VASP) in vitro and in intact human platelets. J. Biol. Chem. 269 (20): 1450914517.

Campbell, G. R., and Campbell, J. H. 1985. Smooth muscle phenotypic changes in arterial wall homeostasis: implications for the pathogenesis of atherosclerosis. Exp. Mol. Pathol. 42 (2): 139162.

Cipolletta, E., Monaco, S., Maione, A. S., Vitiello, L., Campiglia, P., Pastore, L., et al. 2010. Calmodulin-dependent kinase II mediates vascular smooth muscle cell proliferation and is potentiated by extracellular signal regulated kinase. Endocrinology, 151 (6): 2747-2759.

Cui, M. Z., Laag, E., Sun, L., Tan, M., Zhao, G., and Xu, X. 2006. Lysophosphatidic acid induces early growth response gene 1 expression in vascular smooth muscle cells: CRE and SRE mediate the transcription. Arterioscler.Thromb.Vasc.Biol. 26 (5): 1029-1035.

Dubey, R. K., Fingerle, J., Gillespie, D. G., Mi, Z., Rosselli, M., Imthurn, B., et al. 2015. Adenosine Attenuates Human Coronary Artery Smooth Muscle Cell Proliferation by Inhibiting Multiple Signaling Pathways That Converge on Cyclin D. Hypertension, 66 (6): 1207-1219.

Duff, J. L., Marrero, M. B., Paxton, W. G., Schieffer, B., Bernstein, K. E., and Berk, B. C. 1995. Angiotensin II signal transduction and the mitogen-activated protein kinase pathway. Cardiovasc.Res. 30 (4): 511-517.

Eckert, R. E., and Jones, S. L. 2007. Regulation of VASP serine 157 phosphorylation in human neutrophils after stimulation by a chemoattractant. J. Leukoc. Biol. 82 (5): 1311-1321. 
Graves, L. M., Bornfeldt, K. E., Raines, E. W., Potts, B. C., Macdonald, S. G., Ross, R., et al. 1993. Protein kinase $A$ antagonizes platelet-derived growth factor-induced signaling by mitogenactivated protein kinase in human arterial smooth muscle cells. Proc. Natl. Acad. Sci. U S A 90 (21): 10300-10304.

Gros, R., Ding, Q., Chorazyczewski, J., Andrews, J., Pickering, J. G., Hegele, R. A., et al. 2006. The impact of blunted beta-adrenergic responsiveness on growth regulatory pathways in hypertension. Mol. Pharmacol. 69 (1): 317-327.

Gusan, S., and Anand-Srivastava, M. B. 2013. cAMP attenuates the enhanced expression of Gi proteins and hyperproliferation of vascular smooth muscle cells from SHR: role of ROS and ROSmediated signaling. Am. J. Physiol. Cell. Physiol. 304 (12): C1198-1209.

Harbeck, B., Huttelmaier, S., Schluter, K., Jockusch, B. M., and Illenberger, S. 2000. Phosphorylation of the vasodilator-stimulated phosphoprotein regulates its interaction with actin. J. Biol. Chem. 275 (40): 30817-30825.

Hartney, T., Birari, R., Venkataraman, S., Villegas, L., Martinez, M., Black, S. M., et al. 2011. Xanthine oxidase-derived ROS upregulate Egr-1 via ERK1/2 in PA smooth muscle cells; model to test impact of extracellular ROS in chronic hypoxia. PLoS One, 6 (11): e27531.

Hewer, R. C., Sala-Newby, G. B., Wu, Y. J., Newby, A. C., and Bond, M. 2011. PKA and Epac synergistically inhibit smooth muscle cell proliferation. J. Mol. Cell. Cardiol. 50 (1): 87-98.

Indolfi, C., Avvedimento, E. V., Di Lorenzo, E., Esposito, G., Rapacciuolo, A., Giuliano, P., et al. 1997. Activation of CAMP-PKA signaling in vivo inhibits smooth muscle cell proliferation induced by vascular injury. Nat. Med. 3 (7): 775-779.

Iyoda, T., Zhang, F., Sun, L., Hao, F., Schmitz-Peiffer, C., Xu, X., et al. 2012. Lysophosphatidic acid induces early growth response-1 (Egr-1) protein expression via protein kinase Cdelta-regulated extracellular signal-regulated kinase (ERK) and c-Jun N-terminal kinase (JNK) activation in vascular smooth muscle cells. J. Biol. Chem. 287 (27): 22635-22642.

Joshi, C. N., Martin, D. N., Fox, J. C., Mendelev, N. N., Brown, T. A., and Tulis, D. A. 2011. The soluble guanylate cyclase stimulator BAY 41-2272 inhibits vascular smooth muscle growth through the CAMP-dependent protein kinase and cGMP-dependent protein kinase pathways. J Pharmacol. Exp. Ther. 339 (2): 394-402.

Khachigian, L. M. 2006. Early growth response-1 in cardiovascular pathobiology. Circ. Res. 98 (2): 186-191.

Kim, J. E., Kang, Y. J., Lee, K. Y., and Choi, H. C. 2009. Isoproterenol inhibits angiotensin IIstimulated proliferation and reactive oxygen species production in vascular smooth muscle cells through heme oxygenase-1. Biol. Pharm. Bull. 32 (6): 1047-1052.

Kimura, T. E., Duggirala, A., Hindmarch, C. C., Hewer, R. C., Cui, M. Z., Newby, A. C., et al. 2014. Inhibition of Egr1 expression underlies the anti-mitogenic effects of cAMP in vascular smooth muscle cells. J. Mol. Cell. Cardiol. 72: 9-19. 
Lehrke, M., Kahles, F., Makowska, A., Tilstam, P. V., Diebold, S., Marx, J., et al. 2015. PDE4 inhibition reduces neointima formation and inhibits VCAM-1 expression and histone methylation in an Epac-dependent manner. J. Mol. Cell. Cardiol. 81: 23-33.

Liu, Q. F., Yu, H. W., You, L., Liu, M. X., Li, K. Y., and Tao, G. Z. 2013. Apelin-13-induced proliferation and migration induced of rat vascular smooth muscle cells is mediated by the upregulation of Egr-1. Biochem.Biophys.Res.Commun. 439 (2): 235-240.

Lowe, H. C., Fahmy, R. G., Kavurma, M. M., Baker, A., Chesterman, C. N., and Khachigian, L. M. 2001. Catalytic oligodeoxynucleotides define a key regulatory role for early growth response factor-1 in the porcine model of coronary in-stent restenosis. Circ.Res. 89 (8): 670-677.

McCaffrey, T. A., Fu, C., Du, B., Eksinar, S., Kent, K. C., Bush, H., Jr., et al. 2000. High-level expression of Egr-1 and Egr-1-inducible genes in mouse and human atherosclerosis. J.Clin.Invest. 105 (5): 653-662.

Montezano, A. C., Nguyen Dinh, C. A., Rios, F. J., and Touyz, R. M. 2014. Angiotensin II and vascular injury. Curr.Hypertens.Rep. 16 (6): 431.

Nakashima, H., Suzuki, H., Ohtsu, H., Chao, J. Y., Utsunomiya, H., Frank, G. D., et al. 2006. Angiotensin II regulates vascular and endothelial dysfunction: recent topics of Angiotensin II type-1 receptor signaling in the vasculature. Curr.Vasc.Pharmacol. 4 (1): 67-78.

Nguyen Dinh Cat, A., Montezano, A. C., Burger, D., and Touyz, R. M. 2013. Angiotensin II, NADPH oxidase, and redox signaling in the vasculature. Antioxid. Redox. Signal. 19 (10): 1110-1120.

Ohtani, K., Egashira, K., Usui, M., Ishibashi, M., Hiasa, K. I., Zhao, Q., et al. 2004. Inhibition of neointimal hyperplasia after balloon injury by cis-element 'decoy' of early growth response gene-1 in hypercholesterolemic rabbits. Gene Ther. 11 (2): 126-132.

Palmer, D., Tsoi, K., and Maurice, D. H. 1998. Synergistic inhibition of vascular smooth muscle cell migration by phosphodiesterase 3 and phosphodiesterase 4 inhibitors. Circ. Res. 82 (8): 852861.

Potier, M., Gonzalez, J. C., Motiani, R. K., Abdullaev, I. F., Bisaillon, J. M., Singer, H. A., et al. 2009. Evidence for STIM1- and Orai1-dependent store-operated calcium influx through ICRAC in vascular smooth muscle cells: Role in proliferation and migration: FASEB Journal. 23 (8) (pp 2425-2437), 2009. Date of Publication: August 2009.

Rivard, A., and Andres, V. 2000. Vascular smooth muscle cell proliferation in the pathogenesis of atherosclerotic cardiovascular diseases. Histol. Histopathol. 15 (2): 557-571.

Santiago, F. S., Lowe, H. C., Day, F. L., Chesterman, C. N., and Khachigian, L. M. 1999. Early growth response factor-1 induction by injury is triggered by release and paracrine activation by fibroblast growth factor-2. Am.J.Pathol. 154 (3): 937-944.

Seshiah, P. N., Weber, D. S., Rocic, P., Valppu, L., Taniyama, Y., and Griendling, K. K. 2002. Angiotensin II stimulation of $\mathrm{NAD}(\mathrm{P}) \mathrm{H}$ oxidase activity: upstream mediators. Circ. Res. 91 (5): 406-413. 
Shahid, M., Shen, L., Seldin, D. C., Lu, B., Ustyugova, I. V., Chen, X., et al. 2010. Impaired 3',5'cyclic adenosine monophosphate-mediated signaling in immediate early responsive gene $\mathrm{X}$-1deficient vascular smooth muscle cells. Hypertension, 56 (4): 705-712.

Simo-Cheyou, E. R., Tan, J. J., Grygorczyk, R., and Srivastava, A. K. 2017. STIM-1 and ORAI-1 Channel Mediate Angiotensin-II-Induced Expression of Egr-1 in Vascular Smooth Muscle Cells. J. Cell Physiol.

Simo-Cheyou, E. R., Vardatsikos, G., and Srivastava, A. K. 2016. Src tyrosine kinase mediates endothelin-1-induced early growth response protein-1 expression via MAP kinase-dependent pathways in vascular smooth muscle cells. Int. J. Mol. Med. 38 (6): 1879-1886.

Takahashi, T., Kawahara, Y., Okuda, M., and Yokoyama, M. 1996. Increasing cAMP antagonizes hypertrophic response to angiotensin II without affecting Ras and MAP kinase activation in vascular smooth muscle cells. FEBS Lett. 397 (1): 89-92.

Touyz, R. M., and Berry, C. 2002. Recent advances in angiotensin II signaling. Braz. J. Med. Biol. Res. 35 (9): 1001-1015.

Vazquez-Padron, R. I., Mateu, D., Rodriguez-Menocal, L., Wei, Y., Webster, K. A., and Pham, S. M. 2010. Novel role of Egr-1 in nicotine-related neointimal formation. Cardiovasc.Res. 88 (2): 296-303.

Wang, T. R., Yang, G., and Liu, G. N. 2013. DNA enzyme ED5 depletes egr-1 and inhibits neointimal hyperplasia in rats. Cardiology, 125 (3): 192-200.

Xi, X. P., Graf, K., Goetze, S., Fleck, E., Hsueh, W. A., and Law, R. E. 1999. Central role of the MAPK pathway in ang II-mediated DNA synthesis and migration in rat vascular smooth muscle cells. Arterioscler. Thromb. Vasc. Biol. 19 (1): 73-82.

Youreva, V., Kapakos, G., and Srivastava, A. K. 2013. Insulin-like growth-factor-1-induced PKB signaling and Egr-1 expression is inhibited by curcumin in A-10 vascular smooth muscle cells. Can.J.Physiol Pharmacol. 91 (3): 241-247.

Youreva, V., and Srivastava, A. K. 2016. Early Growth Response Protein-1 Expression by InsulinLike Growth Factor-1 Requires ROS-Dependent Activation of ERK1/2 and PKB Pathways in Vascular Smooth Muscle Cells. J. Cell. Biochem. 117 (1): 152-162.

Zhang, J., Sato, M., Duzic, E., Kubalak, S. W., Lanier, S. M., and Webb, J. G. 1997. Adenylyl cyclase isoforms and vasopressin enhancement of agonist-stimulated cAMP in vascular smooth muscle cells. Am. J. Physiol. 273 (2 Pt 2): H971-980.

Zhao, L., Li, A. Q., Zhou, T. F., Zhang, M. Q., and Qin, X. M. 2014. Exendin-4 alleviates angiotensin II-induced senescence in vascular smooth muscle cells by inhibiting Rac1 activation via a cAMP/PKA-dependent pathway. Am. J. Physiol. Cell. Physiol. 307 (12): C1130-1141. 


\section{FIGURE LEGENDS}

Figure 1: Isoproterenol attenuates Ang-II-induced increase in Egr-1 protein and mRNA levels

Quiescent A-10 VSMC were pre-treated in the absence (CTL) or presence of indicated concentrations of ISO for $30 \mathrm{~min}$, followed by stimulation with $100 \mathrm{nM}$ Ang-II for $1 \mathrm{~h}$. A) Cell lysates were immunoblotted with Egr-1 antibody (top panel) or $\beta$-tubulin (middle panel). Bar diagrams represent average data from 5 independent experiments quantified by densitometric scanning of immunoblots. The control is defined as 1 and each value aside is expressed as fold increase compared to the control values. B) Analysis of relative Egr-1 mRNA levels was performed by qRT-PCR. Relative level of Egr-1 mRNA is measured as fold variation compared to the control and normalized with $\beta$-actin level taken as a standard. ${ }^{* * *} p<0.001$ versus control values. ${ }^{\# \#} p<0.001$ versus VSMC treated with Ang-II alone.

Figure 2: Forskolin attenuates Ang-II-induced increase in Egr-1 protein and mRNA levels in A-10 VSMC

Quiescent A-10 VSMC were pre-treated in the absence (CTL) or presence of indicated concentrations of FSK for $30 \mathrm{~min}$, followed by stimulation with $100 \mathrm{nM}$ Ang-II for $1 \mathrm{~h}$. A) Cell lysates were immunoblotted with Egr-1 antibody (top panel) or $\beta$-tubulin (middle panel). Bar diagrams represent average data from 3 independent experiments quantified by densitometric scanning of immunoblots. The control is defined as 1 and each value aside is expressed as fold increase compared to the control values. B) Analysis of relative Egr-1 mRNA levels was performed by qRT-PCR. Relative level of Egr-1 mRNA is measured as fold variation compared to the control and normalized with $\beta$-actin level taken as a standard. ${ }^{* *} p<0.01,{ }^{* * *} p<0.001$ versus control values. ${ }^{\#} p<0.01,{ }^{\# \#} p<0.001$ versus VSMC treated with Ang-II alone.

Figure 3: Blockade of phosphodiesterase activity potentiates the inhibitory effect of isoproterenol on Ang-II-induced Egr-1 expression 
Quiescent A-10 cells were pre-treated with $10 \mu \mathrm{M}$ of the PDE inhibitor, IBMX, alone (A) or in the presence of $10 \mu \mathrm{M}$ of ISO (IBMX + ISO) (B) prior to stimulation with $100 \mathrm{nM}$ Ang-II for $1 \mathrm{~h}$. Cell lysates were probed with Egr-1 antibody (top panels in A and $\mathbf{B}$ ) or $\beta$-tubulin (middle panels). Bar diagrams in each section represent average data from 3 independent experiments quantified by densitometric scanning of immunoblots. The control is defined as 1 and each value aside is expressed as fold increase compared to the control value defined as $1 .{ }^{* *} p<0.01,{ }^{* * *} p<0.001$ versus CTL values. ${ }^{\# \#} p<0.001$ versus VSMC treated with Ang-II alone. ${ }^{+} p<0.05$ comparison between ISO and ISO+IBMX pretreatments.

Figure 4: The phosphorylation levels of VASP inversely correlate with reduced levels of Egr-1 expression in the presence of isoproterenol and isobutylmethylxanthine

Quiescent A-10 cells were pre-treated with $10 \mu \mathrm{M}$ of IBMX alone (A) or in the presence of $10 \mu \mathrm{M}$ of ISO (IBMX + ISO) (B) prior to stimulation with $100 \mathrm{nM}$ Ang-II for $1 \mathrm{~h}$. Cell lysates were probed with total VASP antibody detecting the total VASP protein at $46 \mathrm{kDa}$ and the serine 157 phosphorylated VASP at $50 \mathrm{kDa}$ (top panels in A and B) or $\beta$-tubulin (middle panels). Bar diagrams represent average data from 4 independent experiments quantified by densitometric scanning of immunoblots. The control is defined as 1 and each value aside is expressed as fold increase compared to the control values. $* p<0.05, * * p<0.01, * * * p<0.001$ versus control values. $\# p<0.05$, $\# \# p<0.01, \# \# \# p<0.001$ versus VSMC treated with Ang-II alone.

Figure 5: Dibutyryl cAMP and Benzoyl-cAMP exert similar inhibitory effects on Ang-II-induced Egr-1 expression in A-10 VSMC

Quiescent A-10 VSMC were pre-treated in the absence (CTL) or presence of increasing concentrations of (A) Db-cAMP $(50 \mu \mathrm{M}, 100 \mu \mathrm{M}$ and $500 \mu \mathrm{M})$ or (B) BNZ-cAMP $(0.5$ $\mu \mathrm{M}, 5 \mu \mathrm{M}$ and $50 \mu \mathrm{M}$ ) for $30 \mathrm{~min}$, followed by stimulation with $100 \mathrm{nM}$ Ang-II for $1 \mathrm{~h}$. Cell lysates were immunoblotted with Egr-1 antibody (top panels) or $\beta$-tubulin (middle panels). Bar diagrams represent average data from 5 independent experiments quantified by densitometric scanning of immunoblots. The control is defined as 1 and each value 
aside is expressed as fold increase compared to the control values. ${ }^{*} p<0.05,{ }^{* *} p<0.01$, ${ }^{* * *} p<0.001$ versus control values. ${ }^{\#} p<0.05,{ }^{\# \#} p<0.01,{ }^{\# \#} p<0.001$ versus VSMC treated with Ang-II alone.

Figure 6: Role of PKA signaling in isoproterenol-mediated inhibitory effects on Ang-II-induced Egr-1 expression in A-10 VSMC

Quiescent A-10 VSMC were pre-treated in the absence (CTL) or presence of $10 \mu \mathrm{M}$ of H89 for $30 \mathrm{~min}$ prior to pre-treatment with $10 \mu \mathrm{M}$ of ISO for $30 \mathrm{~min}$, followed by stimulation with $100 \mathrm{nM}$ Ang-II for $1 \mathrm{~h}$. A) Cell lysates were immunoblotted with Egr-1 antibody (top panel) or $\beta$-tubulin (middle panel). Bar diagrams represent average data from 4 independent experiments quantified by densitometric scanning of immunoblots. The control is defined as 1 and each value aside is expressed as fold increase compared to the control values. B) Analysis of relative Egr-1 mRNA levels was performed by qRTPCR. Relative level of Egr-1 mRNA is measured as fold variation compared to the control and normalized with $\beta$-actin level taken as a standard. ${ }^{*} p<0.05,{ }^{* *} p<0.01$, ${ }^{* * *} p<0.001$ versus control values. ${ }^{\#} p<0.05,{ }^{\# \#} p<0.01,{ }^{\# \# \#} p<0.001$ versus VSMC treated with Ang-II alone

Figure 7: Role of PKA signaling in forskolin-mediated inhibitory effects on Ang-IIinduced Egr-1 expression in A-10 VSMC

Quiescent A-10 VSMC were pre-treated in the absence (CTL) or presence of $10 \mu \mathrm{M}$ of H89 for 30 min prior to pre-treatment with $25 \mu \mathrm{M}$ of FSK for $30 \mathrm{~min}$, followed by stimulation with $100 \mathrm{nM}$ Ang-II for $1 \mathrm{~h}$. A) Cell lysates were immunoblotted with Egr-1 antibody (top panel) or $\beta$-tubulin (middle panel). Bar diagrams represent average data from 4 independent experiments quantified by densitometric scanning of immunoblots. The control is defined as 1 and each value aside is expressed as fold increase compared to the control values. B) Analysis of relative Egr-1 mRNA levels was performed by qRTPCR. Relative level of Egr-1 mRNA is measured as fold variation compared to the control and normalized with $\beta$-actin level taken as a standard. ${ }^{*} p<0.05,{ }^{* *} p<0.01$, ${ }^{* * *} p<0.001$ versus control values. ${ }^{\#} p<0.05,{ }^{\# \#} p<0.01,{ }^{\# \#} p<0.001$ versus VSMC treated with Ang-II alone. 
Figure 8: Blockade of PKA reduces isoproterenol-mediated VASP phosphorylation and restores Ang-II-induced ERK1/2 phosphorylation in A-10 VSMC

Quiescent A-10 VSMC were pre-treated in the absence (CTL) or presence of $10 \mu \mathrm{M}$ of H89 for $30 \mathrm{~min}$ prior to pre-treatment with $10 \mu \mathrm{M}$ of ISO for $30 \mathrm{~min}$, followed by stimulation with $100 \mathrm{nM}$ Ang-II for $5 \mathrm{~min}$. A) Cell lysates were probed with total VASP antibody detecting the total VASP protein at $46 \mathrm{kDa}$ and the serine 157 phosphorylated VASP at $50 \mathrm{kDa}$ (top panel), with antibody detecting Thr202 and Tyr204 phosphorylated ERK1/2 (middle panel) as well as with total ERK antibody (bottom panel). Bar diagrams obtained with average data from 5 independent experiments quantified by densitometric scanning of immunoblots represent the fold change in phospho-VASP/Total VASP ratio B) or in ERK phosphorylation C). The control is defined as 1 and each value aside is expressed as fold increase compared to the control values. ${ }^{*} p<0.05,{ }^{* *} p<0.01,{ }^{* * *} p<0.001$ versus control values. ${ }^{\#} p<0.05,{ }^{\# \#} p<0.01,{ }^{\# \#} p<0.001$ versus VSMC treated with Ang-II+ ISO.

Figure 9: Blockade of PKA reduces forskolin-mediated VASP phosphorylation and restores Ang-II-induced ERK1/2 phosphorylation in A-10 VSMC

Quiescent A-10 VSMC were pre-treated in the absence (CTL) or presence of $10 \mu \mathrm{M}$ of H89 for $30 \mathrm{~min}$ prior to pre-treatment with $25 \mu \mathrm{M}$ of FSK for $30 \mathrm{~min}$, followed by stimulation with $100 \mathrm{nM}$ Ang-II for $5 \mathrm{~min}$. A) Cell lysates were probed with total VASP antibody detecting the total VASP protein at $46 \mathrm{kDa}$ and the serine 157 phosphorylated VASP at $50 \mathrm{kDa}$ (top panel), with antibody detecting Thr202 and Tyr204 phosphorylated ERK1/2 (middle panel) as well as with total ERK antibody (bottom panel). Bar diagrams obtained with average data from 5 independent experiments quantified by densitometric scanning of immunoblots, represent the fold change in phospho-VASP/Total VASP ratio B) or in ERK phosphorylation C). The control is defined as 1 and each value aside is expressed as fold increase compared to the control values. ${ }^{*} p<0.05,{ }^{* *} p<0.01,{ }^{* * *} p<0.001$ versus control values. ${ }^{\#} p<0.05,{ }^{\# \#} p<0.01,{ }^{\# \#} p<0.001$ versus VSMC treated with Ang-II+ FSK. 
A
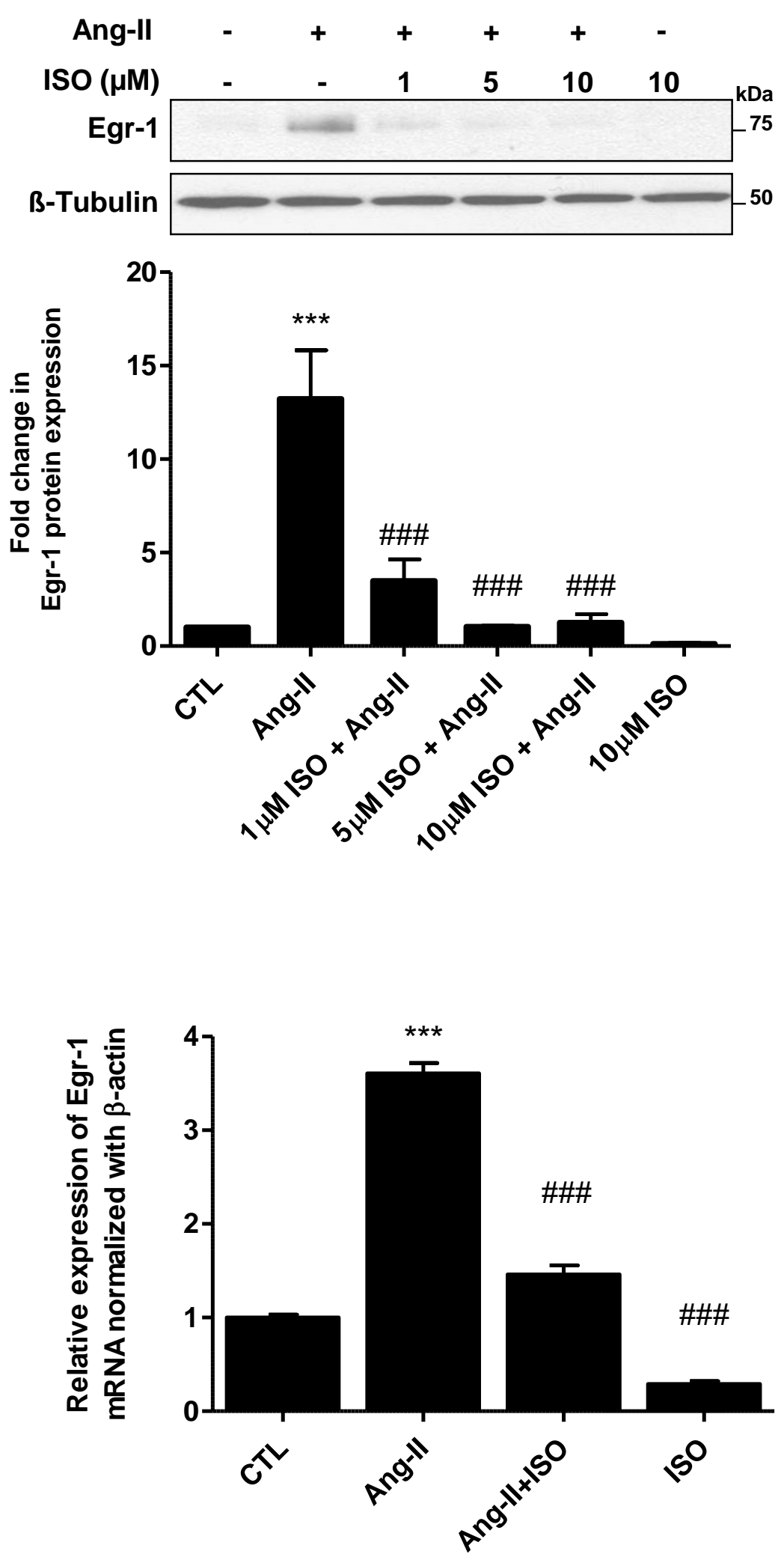
A
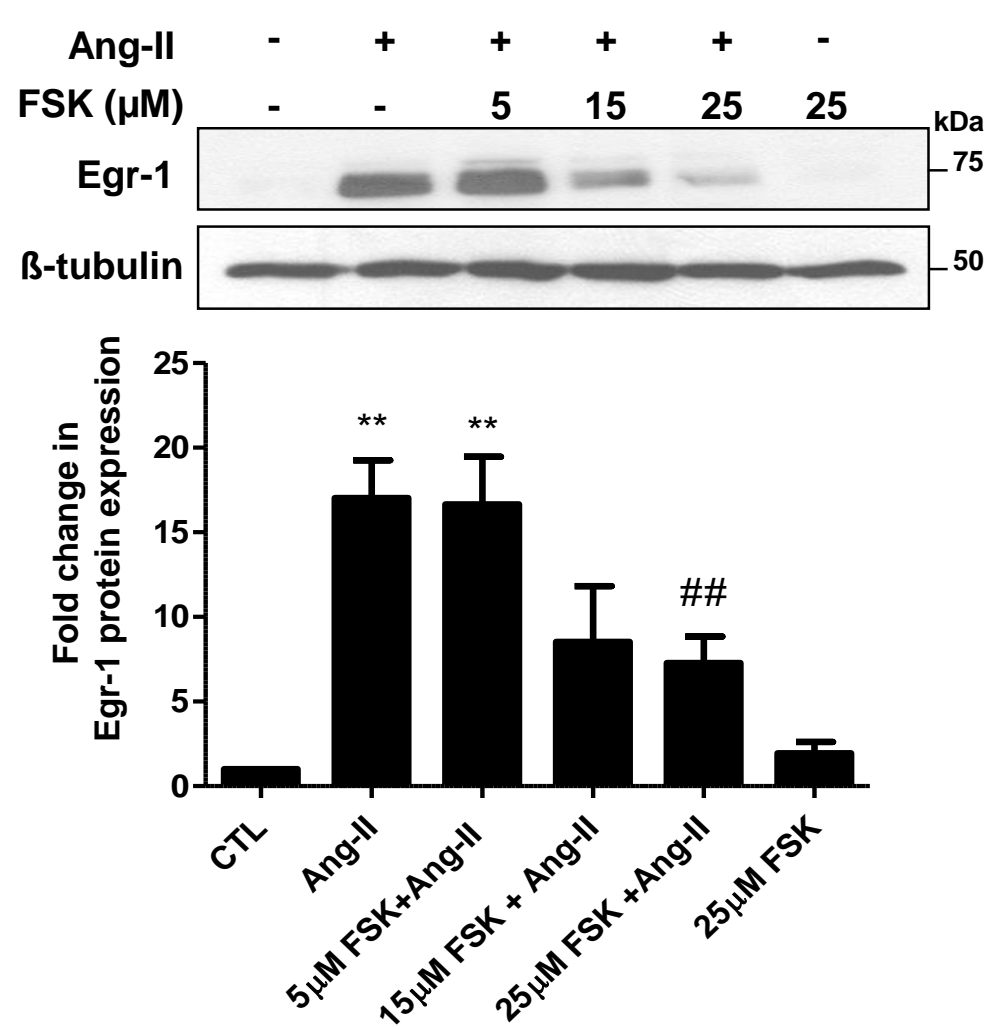

B

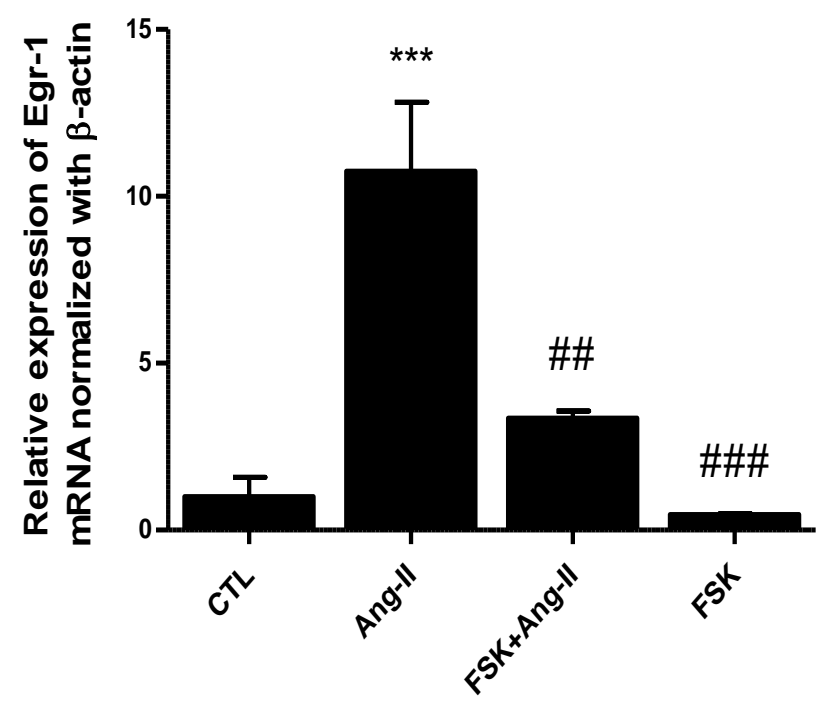


A
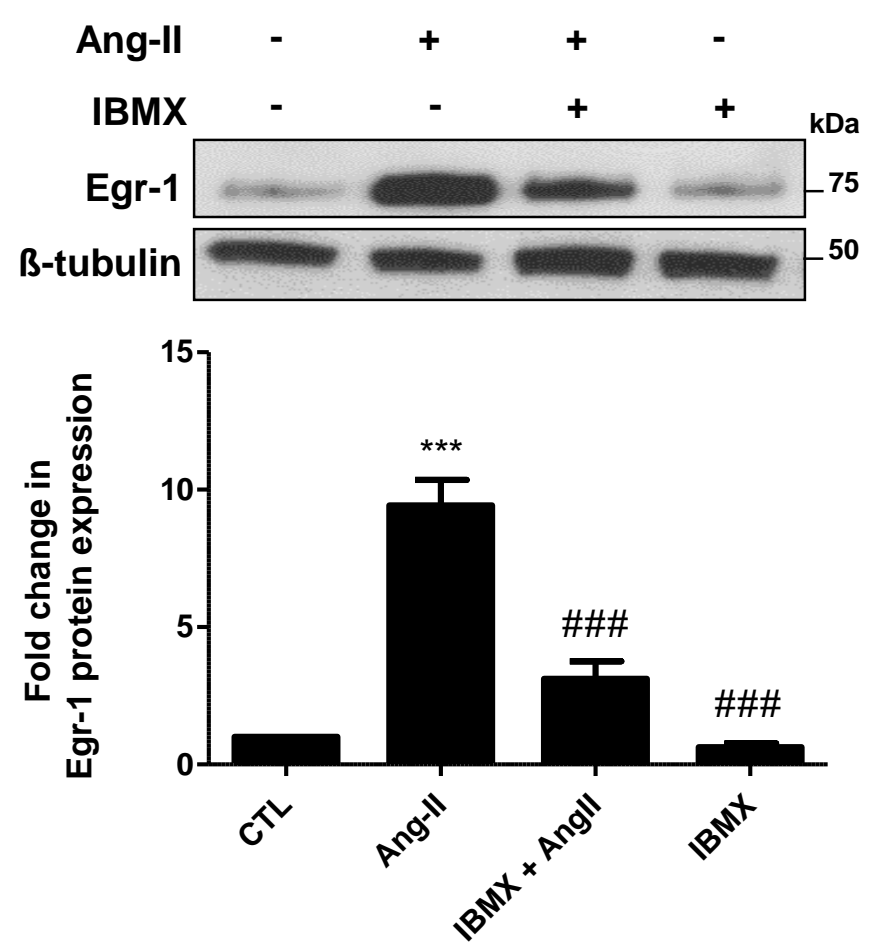

B

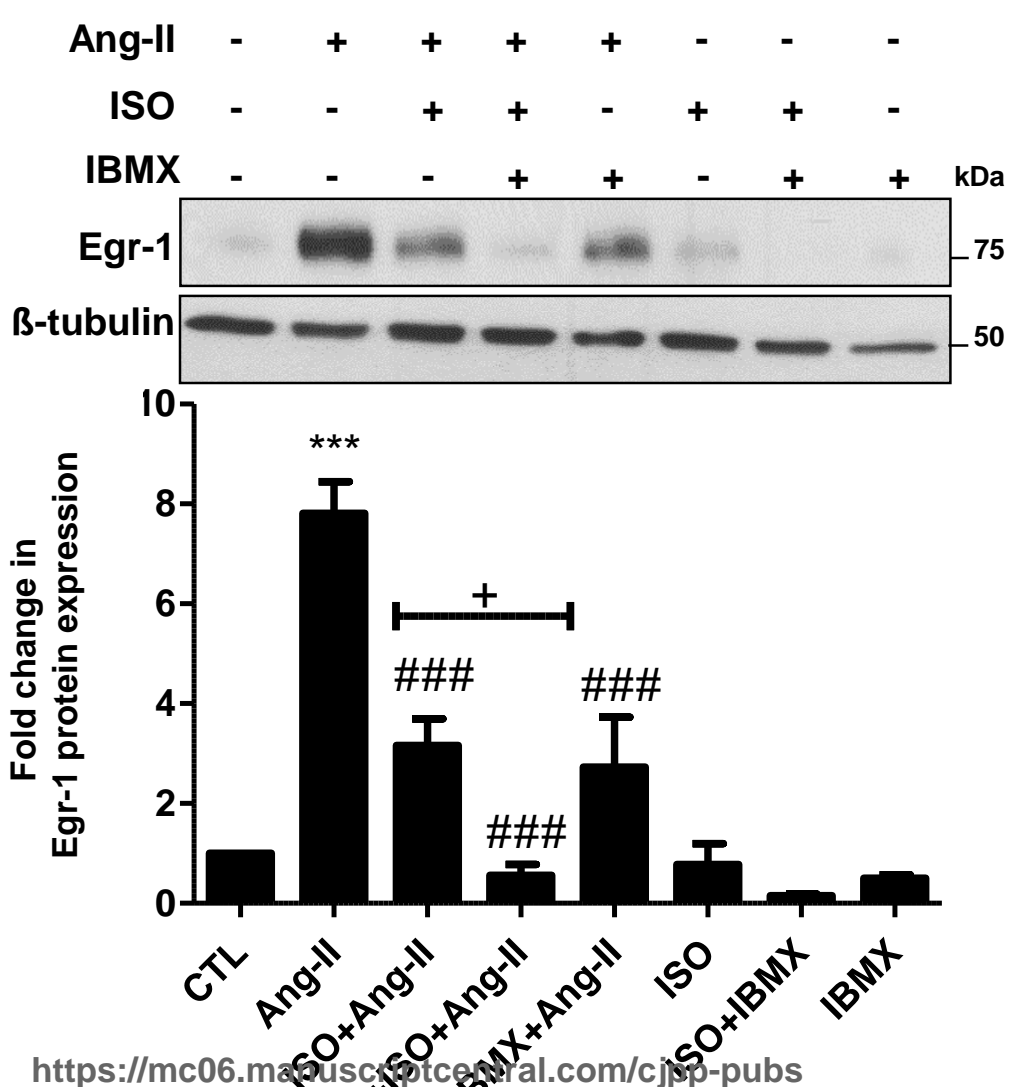


A
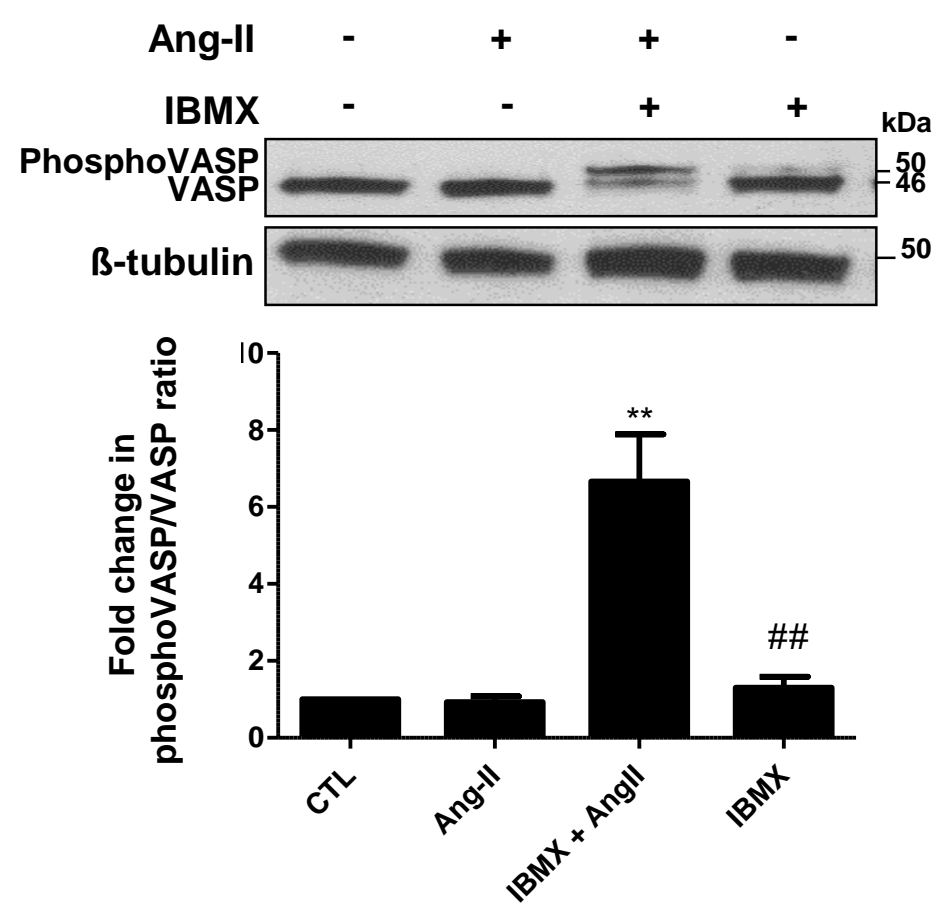

B

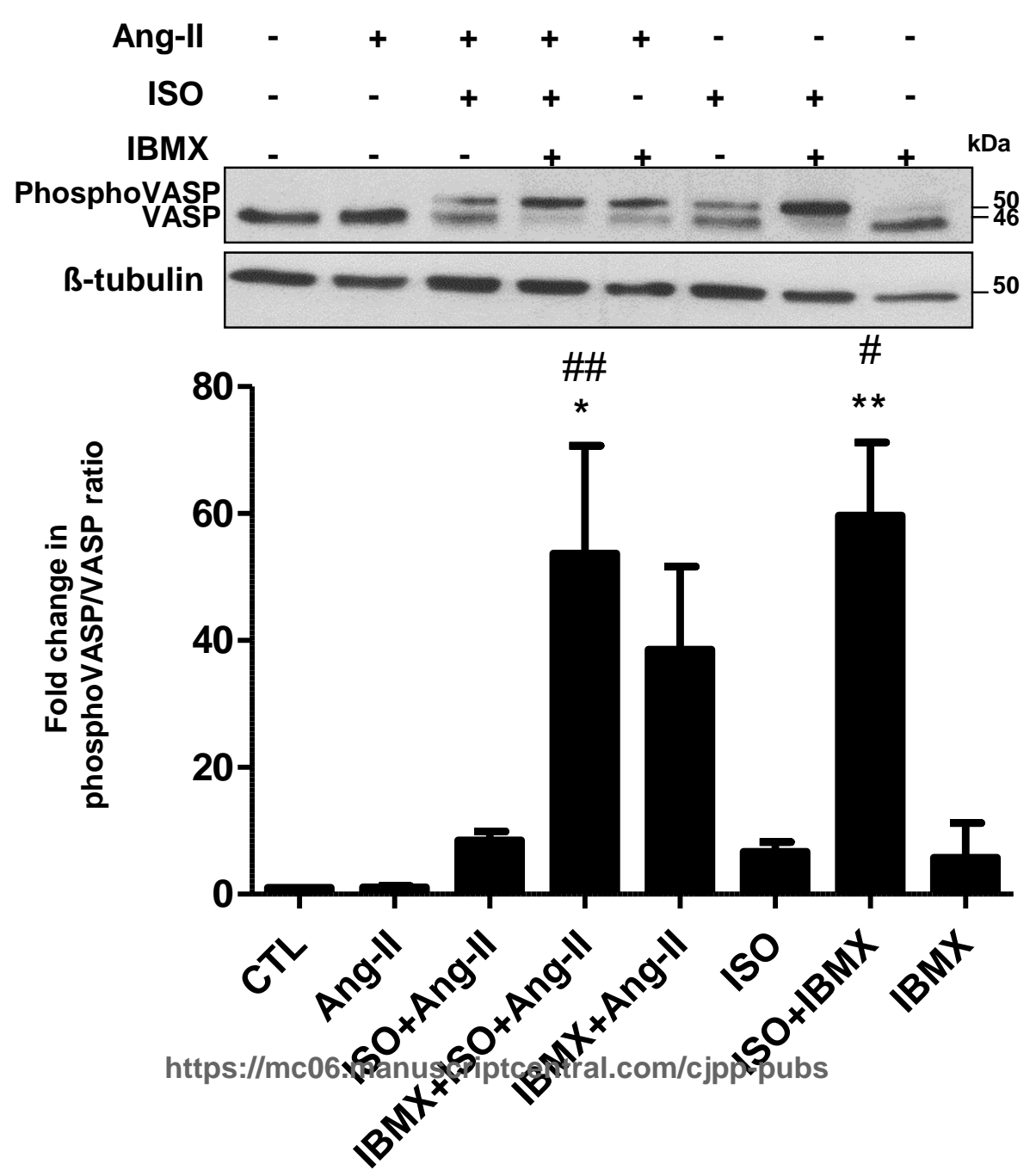



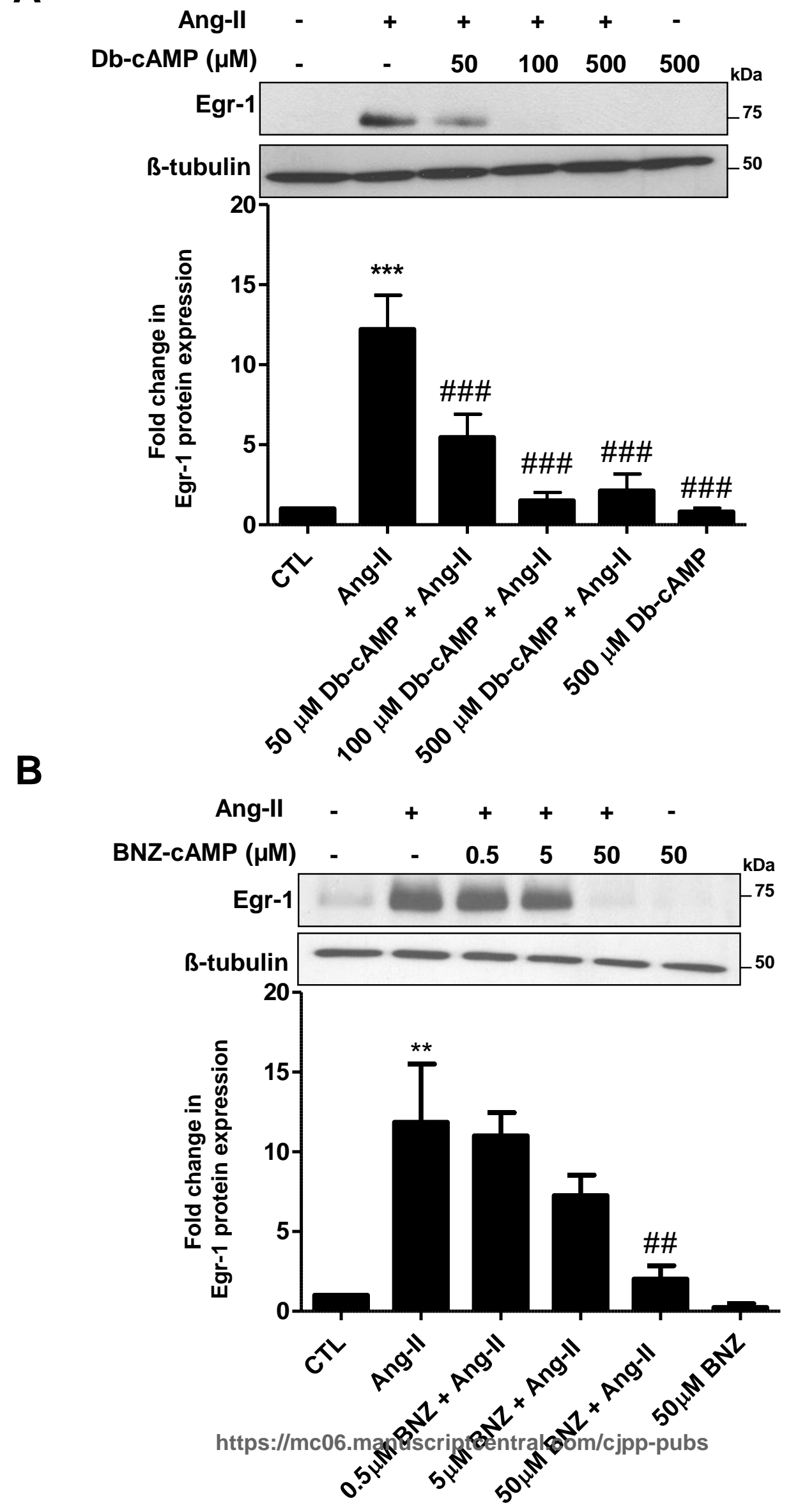
A
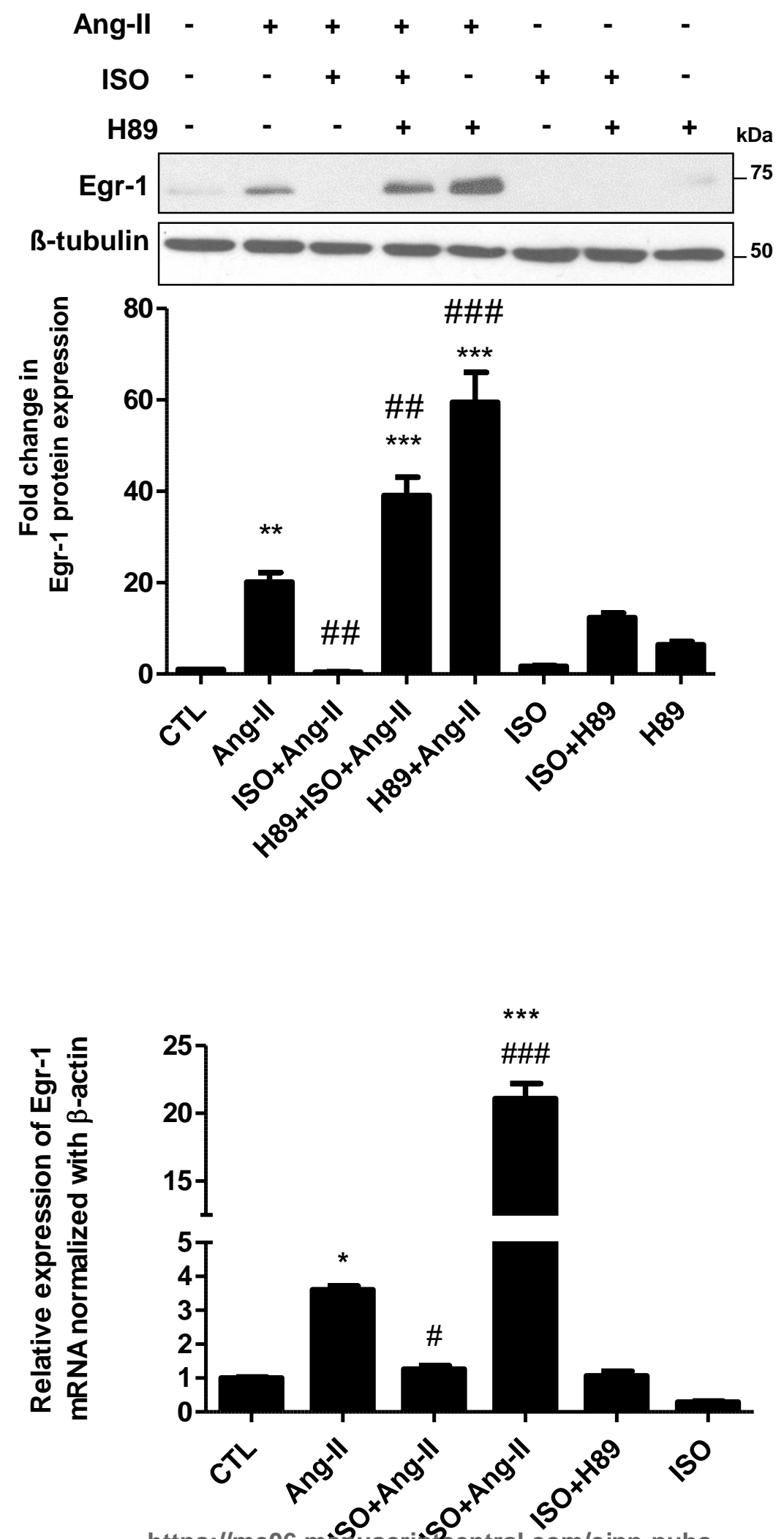
A
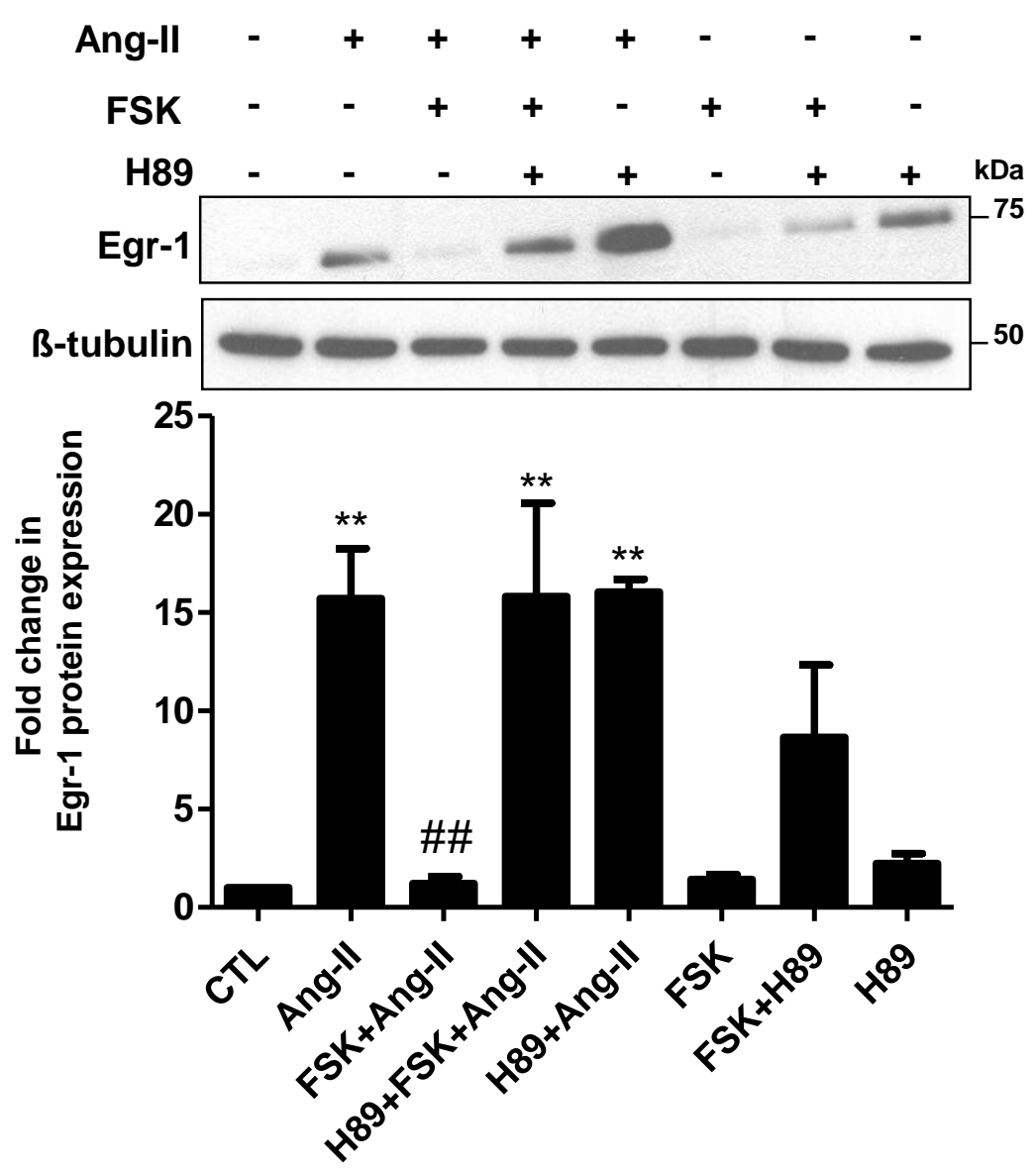

B

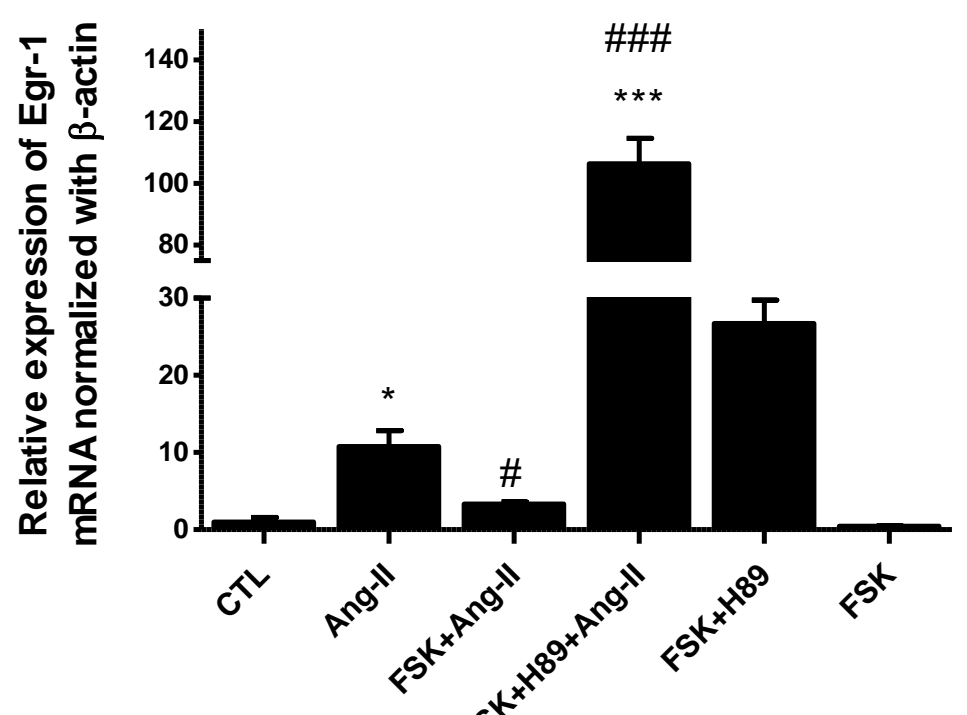


A

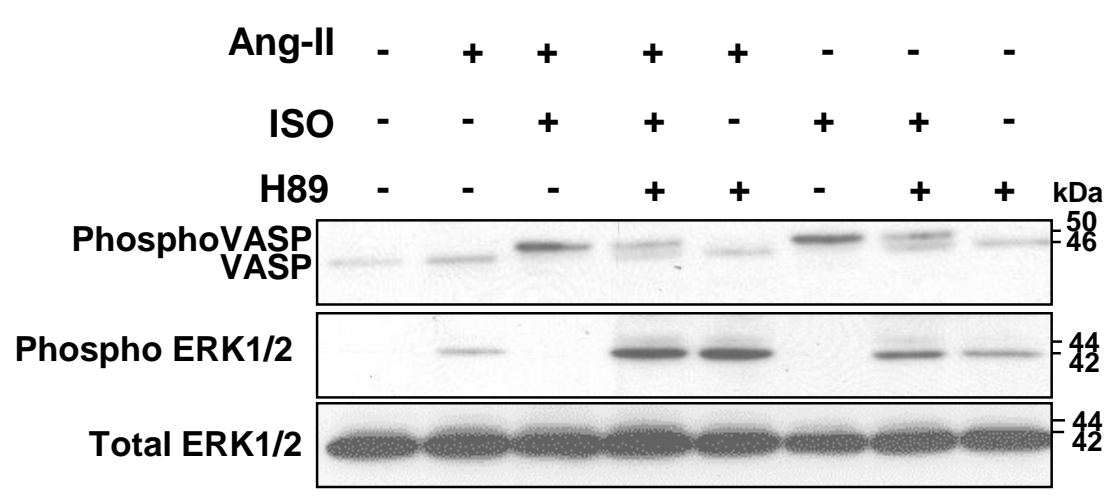

B

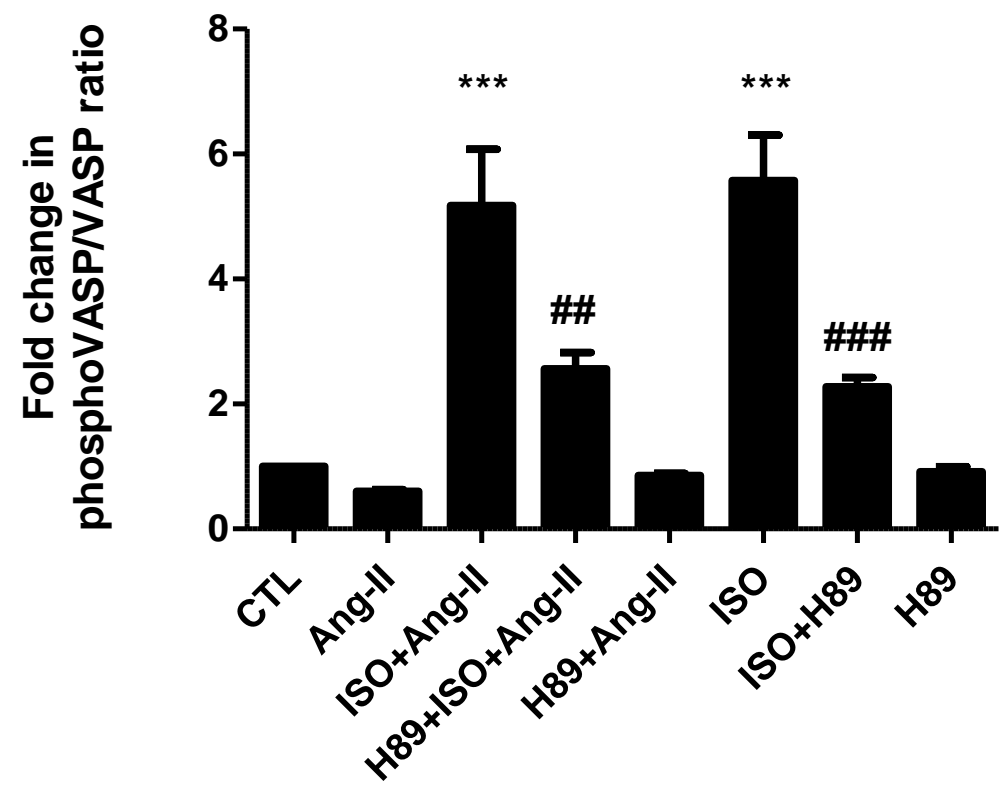

C

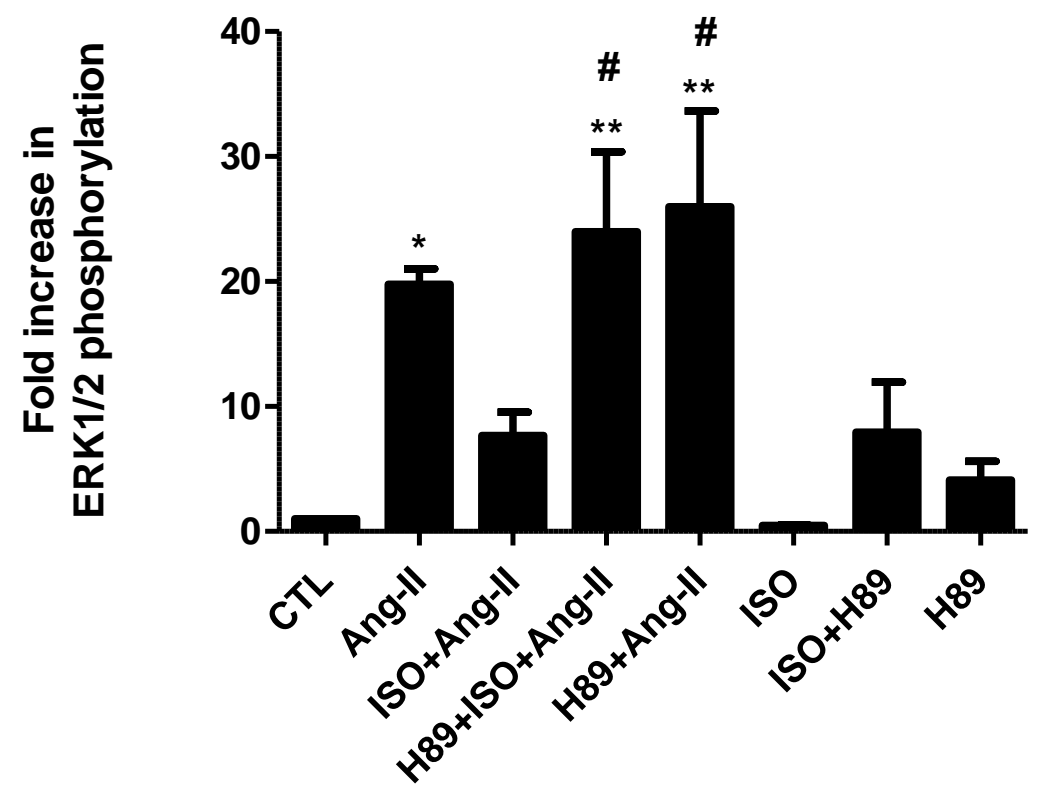


A

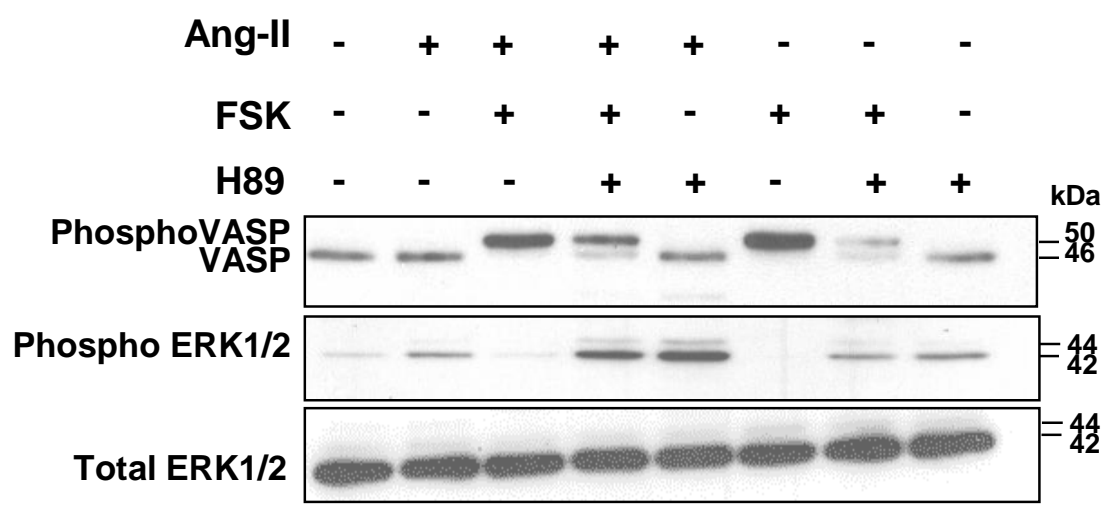

B

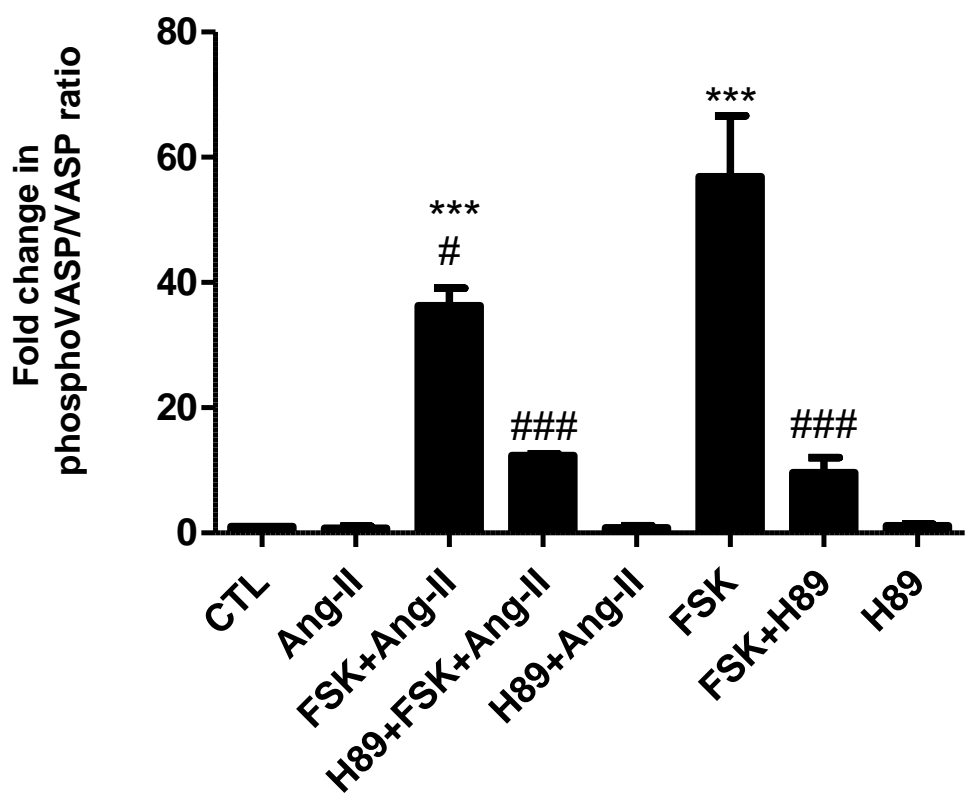

C

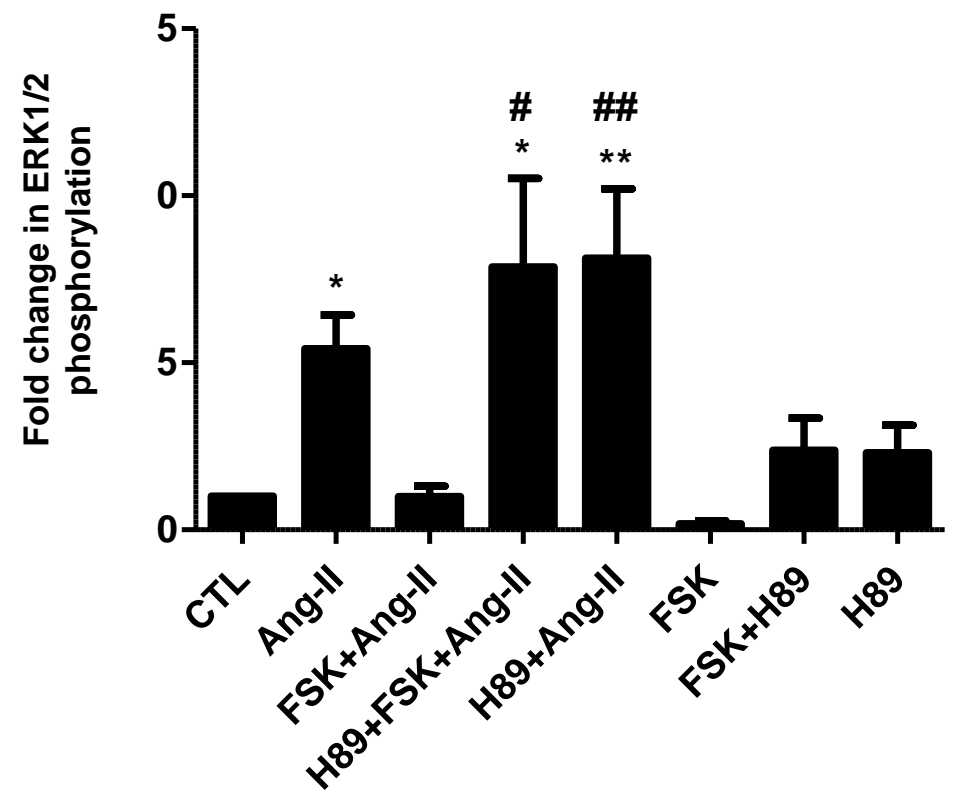

https://mc06.manuscriptcentral.com/cjpp-pubs 